\title{
Censura y expurgo en los incunables de la Biblioteca Histórica de la Universidad de Valencia
}

\section{Censorship and purging in the incunabulum preserved by the Historical Library of de University of Valencia}

Bárbara Barberá Matías barbarma@alumni.uv.es

Universitat de València

Resumen: La Inquisición Española instauró en el s.XVI un modelo sistemático de censura que se mantuvo en vigor hasta su desaparición, buscando imponer una ideología dominante en función de sus propios intereses. La Biblioteca Histórica de la Universidad de Valencia conserva un total de ocho incunables que fueron sometidos a expurgo por diversos motivos y en distintas épocas. Este conjunto de obras supone una buena muestra de la actividad censora llevada a cabo por la Inquisición, que contribuyó a crear una memoria negativa, perjudicando tanto a autores e impresores como a los propios lectores.

Palabras clave: Inquisición Española; incunable; censura; expurgo; ideología; índice inquisitorial

\begin{abstract}
The Spanish Inquisition established a systematic pattern of censorship in the sixteenth century; it maintained a force of purging until its demise seeking to impose a dominant ideology in terms of its own interests. The Historical Library of the University of Valencia keeps eight incunabula which were expurgated for various reasons and at different times. These books are a good example of the censorship activity carried out by the Inquisition, which helped to create a negative memory, harming authors, printers and readers themselves.
\end{abstract}

Keywords: Spanish Inquisition; incunabulum; censorship; expurgate; ideology; inquisitorial index . 
Bárbara Barberá Matías. Censura y expurgo en los incunables de la Biblioteca Histórica

\author{
de la Universidad de Valencia
}

\title{
1.Introducción
}

La Inquisición Española estableció un mecanismo sistemático de censura en el siglo XVI, que se mantuvo en vigor hasta el siglo XIX y que con mayor o menor eficacia influyó en el desarrollo de la cultura contribuyendo de manera decisiva en la formación de la ideología dominante (Pinto Crespo 1980: 516). El Santo Oficio no se encargaba tanto de controlar la producción del libro, ya que la concesión de licencias era potestad de la Corona, sobre todo a partir de la pragmática de 1558 que vino a afirmar esta prerrogativa como exclusiva de la justicia real (Martínez Millán 1980: 560), como de vigilar la circulación y difusión del libro. Su actividad fundamental se producía a posteriori, pero aún así ejercía cierto control sobre las impresiones, pudiendo suspender o prohibir la impresión de una obra (Pinto Crespo 1983: 93). El Santo Oficio controlaba la circulación de los libros desde su entrada en el reino, mediante la vigilancia de puertos y las visitas a navíos, hasta su venta en las librerías. De hecho, la vigilancia de librerías fue desarrollada de manera sistemática introduciendo en 1605 la obligación para todos los libreros de elaborar un inventario de los libros que poseyesen. Este estricto control tuvo consecuencias económicas y personales para los libreros debido a la retención y prohibición de ejemplares. Del mismo modo, tampoco los lectores estaban exentos de vigilancia, ejercida a través de las inspecciones de bibliotecas tanto públicas como privadas. Poseer un libro prohibido era considerado sospecha de herejía y leerlo era castigado con la pena de excomunión, que sólo podía ser absuelta por el Papa o el Inquisidor General (Pinto Crespo 1983: 130).

V. Pinto Crespo describe «el proceso al libro» comparándolo con el proceso ordinario que afectaba a las personas, a pesar de no estar definido legal ni jurídicamente con precisión (Pinto Crespo 1983: 29). Dicho proceso comenzaba con la delación o la denuncia o bien con la interceptación del libro en alguna de las diligencias de control. A continuación procedía la fase de investigación, llevada a cabo por los calificadores del Santo Oficio, con el objetivo de establecer el grado de error contenido en el libro acusado. La decisión que ponía fin al proceso correspondía siempre al Tribunal de la Suprema Inquisición y podía ser positiva, de forma que el libro podía circular libremente, o negativa, en cuyo caso existían dos posibilidades: la destrucción material del libro mediante su quema o el expurgo, es decir, la circulación del libro previamente corregido y expurgado por los agentes calificadores. Esta decisión era publicada en un edicto prohibitorio o carta acordada o bien incluida en el próximo índice de libros prohibidos o expurgados (Pinto Crespo 1983: 63).

Los índices inquisitoriales se introdujeron en España a mediados del s. XVI y cobraron importancia a partir del Concilio de Trento; antes de su aparición las prohibiciones se promulgaban mediante los citados edictos y cartas acordadas, que suponían la forma ordinaria de prohibir obras y nunca dejaron de publicarse (Pinto Crespo 1984: 273). La finalidad de los índices era en última instancia recoger todas las prohibiciones y demás decisiones en materia censora y difundirlas. Aunque tradicionalmente han sido la principal fuente para el estudio de la censura, no son suficientes en sí mismos, tal y como señala J. Pardo Tomás (1991: 334), sino que es preciso contar con otro tipo

SCRIPTA, Revista internacional de literatura i cultura medieval i moderna, núm. 4 / desembre 2014 / pp. 40 - 67 ISSN: $2340-4841 \cdot$ doi:10.7203/SCRIPTA.4.4125 


\section{de la Universidad de Valencia}

de fuentes. En cualquier caso, ofrecen un aspecto esencial: «la realidad exhaustiva de todo aquello considerado por los censores fuera de lo permitido, el universo de lo prohibido» (Pinto Crespo 1983: 49). Es decir, establecen el marco de la censura. Así mismo, los índices reflejan las particularidades de la Inquisición Española, derivadas de su posición al servicio del Estado y al amparo de la Monarquía. Aunque en principio el Santo Oficio hizo suyas las normas del Concilio de Trento en materia de censura siguiendo las directrices de los catálogos publicados fuera de España, pronto comenzó a publicar sus propios catálogos. De hecho, llegó a prohibir obras permitidas por Roma y en el caso contrario, permitió circular obras que habían sido prohibidas en el resto de Europa ${ }^{1}$ (Cerrón Puga 1996).

El primer catálogo publicado en España fue el de 1551, aunque es más preciso hablar de «lista de libros prohibidos», ya que esta primera publicación no tiene aún la entidad de un índice inquisitorial ${ }^{2}$. En 1554 se publicó la Censura General de Biblias o Censura Generalis, una especia de índice temático (Tellechea Idígoras 1962). El primer índice inquisitorial con suficiente entidad e importancia fue el Catálogo de Valdés o Catálogo de 1559, seguido del catálogo de Quiroga (1583-1584) el primero en incluir un índice expurgatorio (en 1583 fue publicado el índice prohibitorio y año siguiente el expurgatorio). Estos dos son reconocidos como los más importantes del s. XVI, que afianzaron el sistema de censura libraria. En el siglo XVII siguieron publicándose índices inquisitoriales, el primero en 1612, completándose posteriormente con dos apéndices uno en 1614 y otro en 1628. En 1632 se publicó el índice más voluminoso y con más censuras hasta el momento, que, sin embargo, originó cierta reacción de oposición que dio lugar al índice de 1640, el último de gran importancia. A comienzos del s. XVIII se publicó el índice de 1707, cuya preparación había comenzado en la centuria anterior, y posteriormente el de 1747, siendo el último índice el de 1790, el cual cambió los criterios metodológicos con respecto a los catálogos anteriores ${ }^{3}$.

En general, durante el s. XVI el objetivo fundamental de la censura en España fue la preservación de la fe, sin adentrarse en cuestiones morales lo que cambió hacia la segunda mitad del s. XVII y sobre todo a partir del s. XVIII, cuando el tribunal de la Inquisición pasó a convertirse en un tribunal de

$1 \mathrm{M}^{\mathrm{o}}$ Luis Cerrón Puga ha estudiado el índice de Quiroga (1583-1584) comparándolo con el de Trento publicado en 1564. El catálogo español parte del tridentino y mantiene en gran parte su espíritu pero revela significativas diferencias, aumenta las prohibiciones y censuras de los escritos de materias doctrinales, espirituales y políticas mientras que se muestra más laxo en lo que respecta a las novelas en prosa, recuperando entre otras obras como el Decamerón (aunque en su versión expurgada de 1572) y el Lazarillo de Tormes y la Celestina, también censurados. (Cerrón Puga 1996).

2 De este primer catálogo se hicieron varias ediciones, que según Martínez de Bujanda, como explica Antonio Márquez, son todas ellas reimpresiones del índice de la Universidad de Lovaina de 1550 que añaden nuevos títulos. Si bien la edición de Toledo difiere y añade una lista de «libros reprobados en lengua castellana» (Márquez 1985: 101).

3 Podemos encontrar una periodización de la censura inquisitorial en la obra de R. García Carcel y D. Moreno Martínez (2000: 320-327), así como un análisis concienzudo de los índices, catálogos y edictos prohibitorios publicados en España en el s. XVI en el libro de V. Pinto Crespo «Inquisición y control ideológico en la España del s. XVI» (1983: 153-228). 
Bárbara Barberá Matías. Censura y expurgo en los incunables de la Biblioteca Histórica de la Universidad de Valencia

la moral pública. Sin embargo, el objetivo último de la censura era el de servir como herramienta de control ideológico. Distintos autores coinciden en que la consecuencia principal de la censura fue la «alteración de los mecanismos de producción intelectual y de los hábitos académicos» (Reyes Gómez 2000: 142).

Ni siquiera los libros editados antes del establecimiento de la Inquisición escaparon a su control. La Biblioteca Histórica de la Universidad de Valencia conserva una pequeña muestra de la censura que afectó a los primeros libros impresos, los incunables. Esta biblioteca cuenta actualmente con uno de los fondos más valiosos de la Comunidad Valenciana, incluyendo importantes manuscritos e incunables que configuran una interesante «síntesis de la cultura europea de las épocas medieval y humanística» (Gimeno Blay 1999: 64). Fue creada en 1785 a partir de la importante donación de Don. Francisco Pérez Bayer. Su fondo ha ido formándose a partir de distintos mecanismos como compras, intercambios y donaciones, coincidiendo el momento más importante con la desamortización de Mendizábal en 1836-1837 cuando un gran número de volúmenes procedentes de los conventos suprimidos ingresaron en la biblioteca, destacando los códices de la Biblioteca Napolitana del Duque de Calabria (Cabeza Sánchez-Albornoz 2000: 68). De los más de 300 incunables que conserva la biblioteca, hemos encontrado ocho que fueron sometidos a expurgo, aunque en todos los casos antes de entrar a formar parte de la biblioteca. Fueron censurados en sus respectivas bibliotecas de origen, en su mayoría centros religiosos.

\section{La censura en los incunables de la Biblioteca Histórica de la Universidad de Valencia}

Tradicionalmente los estudios sobre la censura de libros han partido de los índices inquisitoriales y el análisis de las obras en ellos contenidas, mientras que en el presente trabajo se pretende estudiar la censura partiendo de las obras expurgadas. El expurgo constituyó, de hecho, una de las tareas más ambiciosas a las que se enfrentó la Inquisición (Pardo Tomás 1991: 334). A continuación exponemos la relación de los incunables que según el actual Catálogo de Incunables de la Biblioteca Universitaria de Valencia (Palanca Pons 1981), fueron sometidos a expurgo ${ }^{4}$ :

1. Alighieri, Dante. (1265-1321) La Commedia, / col commento di Cristoforo Landino. Rime diverse. -Venezia : Piero [de' Piasi] Cremonese (18 noviembre, 1491) ; Fol. Sign.: BH Inc. $120(1)$.

4 Palanca Pons, A., García Morales, J., Gómez Gómez, M.D.P. (1981) Catálogo de los incunables de la Biblioteca Universitaria de Valencia. Valencia. Ed. Universidad de Valencia. Según este catálogo la obra de Tito Maccio Plauto, titulada Comoediae (Venecia, Vindelinus de Spira y Johannes de Colonia, 1472), con la signatura BH Inc. 045, fue expurgada, ya que presenta cancelado todo el texto de una de sus páginas. Hemos comprobado que esta cancelación no responde a una labor de expurgo sino a la corrección de un error de imprenta, por lo que no se puede considerar este libro como expurgado o censurado. 
Bárbara Barberá Matías. Censura y expurgo en los incunables de la Biblioteca Histórica de la Universidad de Valencia

2. Ángel de Clavasio, Beato (ca. 1410-1495) Summa de casibus conscientiae. -Lugduni : [MartinusHavard(?)] (19 septiembre, 1500) ; 4 . Sign.: BH Inc. 281.

3. Biblia. Latín. Biblia latina, / cum tabula Gabrielis Bruni. — Venetiis : Simon Bevilaqua (8 mayo 1498) ; $4^{\circ}$. Sign.: BH Inc. 244.

4. Herolt, Johannes (O.P.) (ca. 1380-1468) Sermones Discipuli de tempore. (I). et de sanctis. Promptuaria exemplorum et de miraculis Beatae Virginis Mariae (II). — [Lugduni : Johannes de Vingle] (30 julio, 1497) ; 4 ${ }^{\circ}$.Partes I-II. Sign.: BH Inc. 311.

5. Jacobo de Vorágine, Beato (ca. 1228-1298) Legenda aurea sanctorum. — Venetiis : Antonius de Strata et Marcus Catanellus (1 julio, 1480) ; Fol. Sign.: BH Inc. 214.

6. Platina, Bartolomeo. Vitae Pontificum. - [Venetiis] : Johannes de Colonia et Johannes Manthen (11juni o, 1479) ; Fol. Sign.: 126(2).

7. Rolevinck, Wernerius. Fasciculus temporum, vel Chronica ab initio mundi. - Venetiis : Erhardus Ratdolt (8 septiembre, 1485) ; Fol. Sign.: BH Inc. 195.

8. Virgilio Marón, Publio. Opera (Bucolica, vel Eclogae. Georgica. Aeneis), / cum commentariis Servii Mauri Honorati, Aelii Donati, Christophori Landini et Antonii Mancinelli, addito libro XIII Maphaei Vegii XII Aeneidos. Seudo-Virgilio: Appendix Vergiliana (Moretum.Priapeia et Catalepton. Dirae, cum comm. Domitii Calderini. Copa. Aetna. Ciris.Culex. Elegia in Moecenatem. Omnia haec, cum comm. eiusdem Calderini). Deseipso. Ausonio: De aetatibus animantium (Idyll.V). Seudo-Ausonio: De aerumnis Herculis. De Musarum inventis. De est et non, cum comm. Domitii Calderini. Deviro bono. De rosis nascentibus. Omnia haec cum comm. eiusdem Calderini.Duodecim Sapientes Romae: Carmina plura (De laude hortuli, etc. notata supra ad C.6011). - (Venetiis : Bartholomaeus de Zanis : impens. Lucae Antonii de Giunta (31 julio, 1493) ; Fol. Sign.: BH Inc. 60.

\subsection{Las notas de expurgo}

El primer signo que nos indica que estamos ante un libro censurado son lo que llamaremos «notas de expurgo». Estas notas, que se ubican principalmente en la primera página, anuncian al lector que se encuentra ante un libro que ha sido sometido a expurgo y que, por tanto, contiene errores, según los inquisidores. El estudio de dichas anotaciones nos permite obtener información sobre aquellas personas que llevaron a cabo la censura del libro de acuerdo a lo establecido por la Inquisición y al mismo tiempo sobre las fechas en la que fue realizado el expurgo. La mayoría de las notas señalan el Índice con respecto al cual se procedió a censurar el libro y están firmadas por la persona que llevó a cabo dicha actividad, aunque no todas presentan idéntica información.

En La Commedia de Dante Alighieri (Venecia, 1491) aparece una nota de expurgo en la primera página que dice: «Ad indicem novum ex comisione dominorum inquisitorum Valentie attestor. Frater Michael Guerau Hierominianus». En este mismo libro encontramos otra nota en la última página: «Por mandado de los señores inquisidores, testé y borré lo probibido en estos cantos del Dante conforme a la censura del Santo 
Bárbara Barberá Matías. Censura y expurgo en los incunables de la Biblioteca Histórica

\section{de la Universidad de Valencia}

Officio, oy primero de mayo de 1585. Fr. Juan Vidalis. Mientras que la primera nota está escrita por el calificador del Santo Oficio que manda expurgar la obra, la segunda es obra de la persona que llevó a cabo dicha actividad, es decir, la que realizó el borrado de los fragmentos no permitidos. El calificador podía realizar él mismo la labor de expurgo del libro o bien delegar esta función en otra persona, por ejemplo, uno de los responsables de la biblioteca que conservaba el libro.

Por otro lado, en la Summa angelica de casibus conscientiae de Ángel de Clavasio (Lyon, 1500) aparecen hasta tres notas de expurgo, todas en la primera página: la primera dice «Expurgado conforme al expurgatorio del año 1632. Fr. Bernardino Pérez de Meca»; la segunda, "Expurgado según el expurgatorio del año 1640. Fr. Miguel de Villarrosa» y la tercera, "Revisto por comisión del Santo Officio. Conforme al Expurgatorio del año 1707. Fr. Miguel Sales [rúbrica]». Se trata de anotaciones escuetas que hacen una simple referencia al índice inquisitorial con respecto al cual se realizó la censura, firmadas por su autor, similares a las que encontramos en la portada de los Sermones discipuli de tempore et de sanctis, de Johannes Herolt (Lyon, 1497): «Expurgado según el expurgatorio de 1707, por orden del Santo Oficio. Fr. Francisco del Hoyo [rúbrica]»; en la de la Legenda aurea sanctorum de Jacobo de Vorágine (Venecia, 1480): «Está borrado en este libro lo que se manda borrar en el Apéndice primero del expurgatorio. Fr. Juan Ximeno, comisario[rúbrica]» o en la primera página de la obra de Bartolomeo Platina, las Vitae Pontificum (Venecia, 1479), que dice: «Adbibitae sunt cautiones nixta presciptus novi Indicis expurgatorii anno 1620».

Más información ofrece, en cambio, la anotación que se añade al final de la tabula en el ejemplar de la Biblia Latina, cum tabula Gabrielis Bruni (Venecia, 1498), a saber: «En la cibdad de Sigüenza a primero días del mes de março 1555 annus, antell señor bachiller Juan de Villel, canónigo de Sigüenza, juez. comisario por los señores inquisidores de los obispados de Cuenca y Sigüenza y en presencia de mi el notario infra scripto, se bió y corrigió esta Biblia y quitaron los herrores que tenía conforme a la censura que para ello enviaron los señores del consejo de su Magestad de la Santa General Inquisición en fe de lo qual el dicho señor canónigo lo firmó de su nombre. Juan de Villel canónigo de Sigüenza [rúbrica]. Passó ante mi Alonso [...] notario [rúbrica]». También en la anotación de la primera página de las obras de Virgilio (Venecia, 1493) podemos leer: «Michael Carraça sacre theologie doctor ordinis carmelitarum et santissime inquisitionis valentine et caesaragustanus cualificator. Setabi, 19 iunii 1585». Estas anotaciones, de manera similar a las que encontramos en la obra de Dante, aportan una fecha más exacta e informan sobre los autores del expurgo e incluso, en el caso de la Biblia, del proceso a seguir.

Todas las obras estudiadas presentan notas de expurgo excepto el Fasciculus temporum de Werner Rolevinck (Venecia, 1485) que, por el contrario, no muestra ninguna nota de expurgo a pesar de contener un fragmento de texto cancelado. Esto demuestra cómo no en todos los casos los calificadores actuarían de la misma manera, de hecho, las notas que hemos señalado no son las únicas indicaciones que podían aparecer en los libros expurgados. Generalmente, aunque entre los materiales estudiados no consta ningún ejemplo de ello, el censor tachaba el nombre del autor en la portada del libro, o bien del impresor, traductor, etc. En otros casos escribía junto al nombre «auctor 
damnatus» o hacía algún tipo de referencia a su consideración como hereje ${ }^{5}$. En ocasiones también se hacía mención de la realidad de la obra, permitida previo expurgo (Pons Alós 2012: 354). En definitiva existe una gran variedad de notas de expurgo, todas con la finalidad de anunciar al lector que está ante una obra perseguida.

\subsection{Los agentes calificadores}

Los índices expurgatorios, o bien las cartas acordadas o edictos cuyas prohibiciones eran finalmente incluidas en los índices, determinaban qué obras debían ser expurgadas, qué errores contenían y cómo debían ser subsanados. Cuando hablamos de agentes calificadores nos referimos a aquellos oficiales del Santo Oficio encargados de llevar a cabo las correcciones de dichos errores. En ocasiones, estas correcciones podían ser realizadas por personas no necesariamente pertenecientes al Santo Oficio, en las que los oficiales inquisitoriales delegaban sus funciones para agilizar el trabajo. Esto sucedía, por ejemplo, con motivo de la publicación de un nuevo catálogo (Pinto Crespo 1983: 61).

En la obra de Dante Alighieri la primera nota está firmada por Miguel Guerau (sin indicar fecha) y la segunda, al final del libro, por Fray Juan Vidal, fechada en 1585. Miguel Guerau perteneció a la orden de los Jerónimos, y probablemente Juan Vidal también. Como ya hemos explicado, el primero es el calificador del Santo Oficio que ordena la revisión de la obra, siendo Fr. Juan Vidal el que materialmente se encarga de borrar y tachar los errores contenidos en el libro, según él mismo indica: «testé y borré lo probibido en estos cantos del Dante conforme a la censura del Santo Officio». En el ejemplar de Ángel de Clavasio, la Summa angelica de casibus conscientiae (Lyon, 1500), firman tres censores que han revisado el libro en ocasiones distintas, a saber: Fr. Bernardino Pérez de Meca (según el Índice de 1632) ${ }^{6}$, Fr. Miguel de Villarrosa (según el Índice de 1640) y Fr. Miguel Sales (según el Índice de 1707).

El siguiente volumen estudiado es la Biblia Latina (Venecia, 1498), que, a su vez, fue revisada por el bachiller Juan de Villel, canónigo de la catedral de Sigüenza. Encontramos también a Fr. Francisco

5 En la Biblioteca Histórica de la Universidad de Valencia podemos encontrar algunos ejemplos de otro tipo de notas entre los libros del s. XVI, como ocurre con el ejemplar de Erasmo de Roterdam titulado «Des. Erasmi Rot. In Novuum Testamentum annotationes», impreso en Basilea en 1540 (sign. BH Z-07/03) donde aparecen varias anotaciones manuscritas en la portada. En una de ellas podemos leer: «Auctoris damnati opera [...] cum expurgatione permessa et [...] caute legenda «, y en otra «Opera omnia Erasmi caute legenda, tam multa enim insunt correctione digna, ut viz. omnia expurgati possint», como muestra de otro tipo de anotaciones que podemos encontrar en los libros censurados.

6 Al final del artículo, junto con la bibliografía, se incluye una lista con todos los Índices Inquisitoriales consultados y a los que se hace referencia en el texto del artículo, así como una lista con los incunables trabajados. Tanto los índices como los incunables aparecen reseñados con el título original tal y como aparecen en el CCPBE. 
Bárbara Barberá Matías. Censura y expurgo en los incunables de la Biblioteca Histórica de la Universidad de Valencia

del Hoyo, que se encarga del libro de Johannes Herolt Sermones Discipuli de tempore et de Sanctis (Lyon, 1497), según el Índice de 1707. La nota de expurgo presente en la primera página de la Legenda aurea sanctorum de Jacobo de Vorágine (Venecia, 1480), está firmada por Fray Juan Ximeno. Finalmente encontramos a Miguel Carraça, que formó parte de la Orden de los Carmelitas Descalzos, como censor de la Opera de Virgilio (Venecia, 1493).

\subsection{Los momentos de expurgo}

Las notas de expurgo registradas nos permiten conocer aquellos índices con respecto a los cuales se realizó la censura, en caso de indicarlo, y no tanto la fecha exacta en la que las correcciones de los libros fueron realizadas, ya que tales correcciones no tuvieron que hacerse necesariamente el mismo año en el que se publicó el índice, sino que pudieron haberse ejecutado con posterioridad. Los índices proporcionan en todo caso una datación post quem para las diversas intervenciones.

La variedad en la procedencia de los libros hace difícil rastrear las fechas de expurgo en aquellos libros en los que no consta en las notas, más aún si tenemos en cuenta que desconocemos la procedencia de tres de ellos: la Summa angelica de casibus conscientiae, de Ángel de Clavasio (Lyon, 1500), la Legenda aurea sanctorum de Jacobo de Vorágine (Venecia, 1480) y las Vitae Pontificum de Bartolomeo Platina (Venecia, 1479). En función de estas notas, hemos tratado de establecer distintos momentos de expurgo, consultando los índices inquisitoriales para comprobar si efectivamente las obras estaban incluidas en ellos, de manera que en aquellos casos en los que no contamos con una fecha exacta, podemos situar la fecha de expurgo cerca de aquella en la que se publicó el Índice. Según indica José Pardo Tomás, se establecía un periodo de 90 días tras la publicación de un nuevo Índice para realizar las labores de expurgo, pero lo normal era que esas tareas se prolongasen en el tiempo (Pardo Tomás 1991: 45). Por otro lado, no en todos los casos ha podido localizarse la mención al expurgo de la obra en cuestión. Hay que tener presente que la censura pudo estar motivada por algún decreto o carta acordada, sabiendo que estas prohibiciones y mandatos debían ser posteriormente recogidos por los índices inquisitoriales.

El primer momento de expurgo corresponde a mediados del s. XVI, época en la que se publican los primeros índices expurgatorios en España y al mismo tiempo los más importantes. Por orden cronológico, el primer libro censurado es la Biblia latina, cum tabula Gabrielis Bruni (Venecia, 1498), corregida en 1555, probablemente con motivo de la publicación de la Censura General de Biblias de 1554 según se dice en la nota de expurgo: «corrigió esta Biblia y quitaron los herrores que tenia conforme a la censura que para ello enviaron los señores del consejo de su Magestad de la Santa General Inquisición». Esta censura afectaba a un total de 70 biblias, según indica Virgilio Pinto Crespo y en ella se hace mención a los muchos sumarios y títulos que contienen errores, lo que permite pensar que el expurgo se llevó a cabo de acuerdo con dicha censura, ya que los fragmentos cancelados se encuentran en los sumarios, como veremos más adelante. En segundo lugar, encontramos dos 
Bárbara Barberá Matías. Censura y expurgo en los incunables de la Biblioteca Histórica

\section{de la Universidad de Valencia}

obras censuradas en 1585: La Comedia, de Dante Alighieri (Venecia, 1491) y la Opera de Virgilio (Venecia, 1493). En el texto de La Commedia la nota de expurgo dice: «testé y borré lo probibido en estos cantos del Dante conforme a la censura del Santo Officio, oy primero de mayo de 1585», mientras que la nota que aparece en la obra de Virgilio está datada en Xátiva, a 19 de junio de 1585. La primera obra está incluida en el Índice Expurgatorio de Quiroga publicado en 1584, en el que se mandan borrar los comentarios de Cristoforo Landino a la Comedia de Dante . El ejemplar de la obra de Virgilio nos da una fecha exacta, por lo que el momento de expurgo está claro y guarda relación con el índice mencionado, el Índice de Quiroga.

En el s. XVII encontramos en primer lugar la obra de Bartolomeo Platina, Vitae Pontificum (Venecia, 1479), censurada en 1620 según la nota de expurgo. El índice más cercano a esta fecha es el de 1612, sin tener en cuenta el apéndice de 1614, por lo que probablemente la censura se realizara conforme a este índice, pero años después de su publicación. La siguiente obra, la Summa angelica de casibus conscientiae de Ángel de Clavasio (Lyon, 1500) fue revisada en tres ocasiones: de acuerdo con el Índice de Zapata de 1632, con el Índice de Sotomayor de 1640 y finalmente ya en el siglo XVIII, de acuerdo con el Índice de 1707, en los tres casos hemos podido verificar que efectivamente la obra de Clavasio estaba incluida en los mencionados catálogos expurgatorios. La Legenda aurea sanctorum de Jacobo de Vorágine (Venecia, 1480), se incluye en el apéndice al Índice de 1612, publicado en 1614, dado que en la nota de expurgo se afirma: «Está borrado en este libro lo que se manda borrar en el Apéndice primero al expurgatorio», en el que efectivamente se incluye la obra, por lo que la fecha de expurgo sería posterior a 1614. Por último contamos con otra obra censurada también en función del catálogo de 1707, Los Sermones Discipuli de tempore et de sanctis, de Johannes Herolt (Lyon, 1497), según especifica la nota de expurgo y hemos comprobado.

En cuanto al Fasciculus Temporum, de Werner Rolevinck, nos ha sido más difícil establecer una fecha de expurgo ya que no incluye ninguna nota que facilite el trabajo de búsqueda. Probablemente fue censurado con posterioridad al año 1640, ya que hemos localizado menciones expresas a esta obra, que coinciden con la intervención que se ha llevado a cabo sobre el libro, en los Índices de 1640 y 1707, sin embargo, no podemos llegar a una conclusión sobre una fecha más exacta.

\subsection{Los textos censurados}

La segunda intervención que encontramos consiste en la anulación de fragmentos del texto, que pueden ir desde una sola palabra hasta páginas completas. El calificador procedía a cancelar el texto tachándolo y, en ocasiones, cubriéndolo con fragmentos de papel. También podía incluir notas al margen. Esta actividad era realizada generalmente según las indicaciones de los índices expurgatorios o edictos que a tal efecto detallaban los pasajes que debían ser borrados por contener errores. Es la acción que supone un mayor daño para el libro ya que afecta directamente a su contenido, pudiendo llegar incluso a alterarlo materialmente contribuyendo al deterioro del papel.

SCRIPTA, Revista internacional de literatura i cultura medieval i moderna, núm. 4 / desembre 2014 / pp. 40 - 67 ISSN: 2340-4841 $\cdot$ doi:10.7203/SCRIPTA.4.4125 
Bárbara Barberá Matías. Censura y expurgo en los incunables de la Biblioteca Histórica

\section{de la Universidad de Valencia}

Para la realización de este trabajo hemos analizado todas las intervenciones presentes en cada uno de los incunables censurados, identificando los fragmentos silenciados y recuperando el texto perdido a partir de otros ejemplares sin censurar, ya se trate de obras conservadas en la propia Biblioteca Histórica de la Universidad de Valencia, como conservadas en otras bibliotecas, habiendo constituido un recurso frecuente el repositorio digital de la Bayerische Staatsbibliothek.

La primera obra que hemos considerado ha sido la edición de la Divina Comedia de Dante Alighieri (Florencia, 1265 - Ravena, 1321) ${ }^{7}$ publicada en 1491 con el título La Commedia, comentada por el humanista italiano Cristoforo Landino (Florencia, 1424-Casentino, 1498). Esta edición incluye también las Rime diverse, que se refieren a la introducción en latín titulada AdDantem gratulatio escrita por el filósofo Marsilio Ficino (Fifline Valdarno, 1433-Careggi, 1499). El ejemplar forma parte de una encuadernación facticia junto con la obra del poeta clásico Publio Papinio Estacio (ca. 45 d.C.96 d.C.) titulada Aquileida, impresa en $1485^{8}$, y procede de la Biblioteca de San Miguel de los Reyes, lo que sabemos gracias a una nota manuscrita de procedencia.

Dante, considerado uno de los autores más importantes del momento de transición entre la época medieval y el Renacimiento, participó activamente en la lucha entre güelfos y gibelinos, decantándose por los primeros. Sus obras tuvieron que enfrentarse a la censura inquisitorial, no sólo a la española, desde muy pronto. De Monarchia, donde exponía su ideal política propugnando la separación de los poderes de la Iglesia y el Estado, fue incluida en los índices romanos anteriores a 1583 y también en el catálogo prohibitorio publicado en España en este mismo año, conocido como el Índice de Quiroga. Sin embargo la obra que ahora tenemos ante nosotros, La Commedia, no se incluye en este último índice debido a su autor, sino debido al comentario añadido por el humanista Cristoforo Landino. En el fol. 72 del Índice de Quiroga, de 1584 se dice:

De Crbistophoro Landino en la Comedia y cantos del Dante. En el argumento del canto 3 del infierno, fol. 17, en los impressos en Venecia por Juan Batista Marchio, año de 1564, quitese desde donde dize: "Tra li quali connobe», hasta, «Rifiuto del'Papato». En el canto decimo del infierno, fol. 60, quitese desde donde dize: «La onde non si debe», hasta, «quanto si pùo».

El texto que nosotros tratamos no está impreso en 1564, ni por el impresor que aquí se nombra, pero parte del texto cancelado coincide con el que se manda borrar y como ya se ha explicado,

\footnotetext{
7 La información biográfica se ha obtenido, en el caso de los autores italianos a partir del Dižionario biográfico degli italiani (1960-2000) Roma, Ed. Istituto della Enciclopedia Italiana y de la enciclopedia italiana online Treccani (http://www. treccani.it/), mientras que para los autores alemanes se ha utilizado además de Treccani, el Lexikon des mittelalters (19771998) Munchen, Ed. Lexma. Para los autores clásicos se ha consultado Kenney, E.J. y Clausen, W.V. (eds.) (1989-1990) Historia de la literatura clásica latina. Madrid, Ed. Gredos. T.II. También se ha consultado el VIAF (Virtual International Authority File) y la enciclopedia Espasa-Calpe (VV.AA. (2003) Enciclopedia universal ilustrada europeo-americana. Madrid, Ed. Espasa-Calpe).

8 Que aparece reseñada en el «Catálogo de los incunables de la Biblioteca Universitaria de Valencia» de la siguiente manera: Estaci, Publi Papini. Achilleis: cum comentario Johannis Britanici. Brixiae: Jacobus Britannicus. (21 mayo, 1485), con la signatura: BH Inc. 120 (2).
}

SCRIPTA, Revista internacional de literatura i cultura medieval i moderna, núm. 4 / desembre 2014 / pp. 40 - 67 ISSN: 2340-4841 · doi:10.7203/SCRIPTA.4.4125 


\section{de la Universidad de Valencia}

una de las notas de expurgo está fechada en el año 1585 y la otra se refiere «ad novum indicem» (al nuevo índice), por lo que con toda probabilidad el censor partió de esta mención. Sin embargo, el calificador, en nuestro caso, va más allá y además de estos versos borra otros muchos, no sólo en el comentario, sino también en el propio texto de la Comedia. El libro fue probablemente expurgado en el Monasterio de San Miguel de los Reyes, ya que los censores pertenecían a la orden de los jerónimos, que habitaba el monasterio en la fecha en que se realizó el expurgo.

La obra presenta múltiples pasajes cancelados y otros muchos cubiertos por fragmentos de papel. Es difícil conocer los motivos, pero sí que podemos llegar a entender la censura, una vez vistos los pasajes anulados. En la mayoría de los casos lo que se trata de borrar son manifiestas críticas hacia el papado, por tanto, estamos ante una censura más de tipo político que moral. Dante se caracterizó además por su profunda religiosidad y rigor moral (Alighieri 1993: 23), por lo que es difícil que sea cuestionado en este sentido. En la Comedia, Dante plasma su particular visión política, que se ve reflejada especialmente en el Purgatorio. El autor recuerda la idea según la cual el hombre tiende a alcanzar la felicidad en la vida terrenal para conseguir la salvación después de la muerte. Para ello es necesario que la paz impere en la tierra y que se impidan las guerras y los enfrentamientos políticos. Fue por esto por lo que Dios creó dos autoridades: el Imperio y la Iglesia, que velasen por que la paz fuese universal. Sin embargo, el Imperio no está exento de los peligros ligados a la naturaleza humana y sólo al Emperador compete la tarea de combatir la maldad de los hombres para que reine la paz, es «el único que puede remediar una necesidad tan esencial para el género humano» (Alighieri 1993: 43). Por otro lado, la avaricia y codicia de los pontífices ha hecho que estos abandonen su misión espiritual, preocupándose sólo del poder temporal, lo que a su vez les ha llevado a posesionarse los bienes y poderes del Imperio, así como los derechos sólo concernientes al Emperador. De aquí se deriva la visión de la separación entre la Iglesia y el Estado que propugna Dante. Para ilustrar esta situación el poeta utiliza recursos como la condena de la actuación política de Felipe IV de Francia (1268-1314) o el enmascaramiento de la mala conducta de Bonifacio VIII (ca.1235-1303) o de Clemente V (1264-1314), bajo la alegoría de la prostituta (Alighieri 1993: 46). Precisamente son los pasajes referentes a Bonifacio VIII los que más se censuran.

Por ejemplo, en el canto undécimo del Infierno se borra el texto siguiente: «Anastasio Papa guardo, lo qual trasse Fotino della via dritta» que forman parte de una inscripción que encuentran Dante y Virgilio en su viaje por el infierno. Se borra también la parte del comentario correspondiente. En este fragmento Dante se refiere a Anastasio II, el que fuera Papa entre el 496 y el 498 y que según una tradición no comprobada aceptó las doctrinas de Fotino de Tesalónica, quien negaba el nacimiento divino de Cristo. Con este tipo de críticas el poeta nos muestra además su profundo pensamiento religioso. Mientras, en el canto XXXII del Purgatorio se tacha todo el comentario que explica el episodio del papa Bonifacio VIII con la prostituta, al que se vuelve a hacer referencia en el canto siguiente, también tachado. En esta parte del texto, Dante narra como la Iglesia había acrecentado su poder y riqueza con los dones de Constantino, convirtiéndose en un monstruo víctima de los siete pecados capitales y que es representado alegóricamente en el texto. Aparece también una ramera, 


\section{de la Universidad de Valencia}

en principio protegida por un gigante, pero que luego la atormenta. Dante está simbolizando a la Curia romana, dispuesta a entregarse al mejor postor en la figura de la ramera y a Felipe IV de Francia, como se explica en el comentario, en la figura del gigante, con quien Bonifacio VIII había estado aliado. En el canto noveno del paradiso, se vuelve a cancelar una parte del comentario en la que de nuevo se hace referencia a este episodio. En este caso Dante vuelve a acusar a la Curia y al papado de acumular riqueza y llama adultero a Bonifacio VIII.

En el s. XVI la actitud de la Inquisición Española estaba destinada en primera instancia a la defensa de la fe, observando fundamentalmente cuestiones de doctrina y no será hasta más tarde cuando comience a inmiscuirse en cuestiones morales prohibiendo obras obscenas y de mal gusto. Por otro lado, la censura política siempre está de alguna manera presente, dada la relación de la institución con la Monarquía a la que sirve y en quien se apoya. Lógicamente, esta visión de los papas no se corresponde con la historia oficial defendida por la Iglesia, en un momento en que las tesis de Lutero han triunfado en parte de Europa, lo que explica en gran parte el expurgo que encontramos en el obra de Dante datado en 1585, cuando la mayor preocupación de la Inquisición en materia censoria es la entrada las ideas de los herejes en España.

A diferencia de la obra de Dante, la obra del franciscano Ángel de Clavasio (Chivasso, ca. 1410-Cuneo, 1495), la Summa de casibus conscientiae, solo presenta un fragmento censurado. Este autor fue conocido por la pureza en su estilo de vida y su santidad, cualidades que le valieron el favor de la Santa Sede llegando a ser nuncio apostólico de Sixto IV y de Clemente VIII. Su fama se debe precisamente a esta obra, que él llamó angelica, un tratado de tipo teológico y moralista conformado como un diccionario o guía sobre cuestiones morales, que sin embargo no gustó en el mundo protestante donde se la llegó a llamar Angelica plus quam diabolica. A pesar de todo, en el Índice de 1632 se incluye a Ángel de Clavasio como autor de segunda clase, aquellos cuyas obras es posible leer previo expurgo. Concretamente, en el fol. 45r, se dice:
Angelus de Clavasio. Eius Summa, quae dicitur Summa Angelica. Venet. 1490, 1569 et Lugduni apud
Theobaldum Paganum. In verbo luxuria, num. 2. V. sit. T.M.: «si solutam fornicatio, etc.» dele, «sed ego non credo quia solum est contra unam prohibitionem, scilicet, non concupisces uxorem proximi tui».

Esta misma mención se localiza, con las mismas palabras, en los Índices de 1640 (aparece en la p.47 de dicho índice) y de 1707 (en este caso en la p.39). El pasaje que se manda borrar coincide exactamente con el que se ha censurado. La Summa angelica de casibus conscientiae está presentada como una especie de diccionario de casos y ejemplos sobre cuestiones de moral, que forma parte de un tipo de literatura importante en la época y que sería muy útil para los confesores. Ángel de Clavasio está exponiendo los distintos casos en los que habría que considerar que se está cometiendo el pecado de la lujuria. Concretamente, se borra la línea en la que contradice el evangelio de Mateo. La lujuria es considerada por la Iglesia Católica como un pecado capital y según el evangelio de Mateo no sólo cometer adulterio es pecado, sino tan sólo mirar con deseo a una mujer lo es, pues del mismo modo es visto como adulterio: «Ego autem dico vobis: quia omnis qui viderit mulierem ad concupiscendum 
Bárbara Barberá Matías. Censura y expurgo en los incunables de la Biblioteca Histórica de la Universidad de Valencia

eam, jam moechatus est eam in corde suo» [Mat. 5, 28]. Ángel de Clavasio difiere en cierto sentido, viene a señalar que el pecado en este caso está definido por una única prohibición, la de desear a la mujer del prójimo: «sed ego non credo, quia solum est contra unam probibitionem, non concupisces proximi tui uxorem, vel contra aliud» (Fol. CCXXXIX). No se admite una opinión que contradiga la doctrina canónica de la Iglesia, por tanto, aunque pueda parecer que estamos ante una censura de carácter moral se trata más de una cuestión dogmática. La obra de Clavasio no contiene ningún aspecto moralmente pernicioso, sino que al contrario, se limita a explicar con ejemplos aquellos conceptos que los católicos deben conocer, especialmente los confesores en el momento de considerar o no pecado las actuaciones de sus fieles.

Entre las obras que estudiamos también se halla una edición de la Biblia Latina, publicada en Venecia en 1498, procedente del Convento de San Agustín de Valencia ${ }^{9}$. Esta edición de la Biblia latina comienza con varios textos bíblicos. En la primera hoja se incluye el siguiente título: «Biblia cum tabula nuper impressa, et cum summariis noviter editis». En el verso de la página de título hay una breve introducción que comienza: «Ad evidentiam sequentis tabulae notandum est, quod in ipsa sunt versus ducenti doudecim, complectentes omnia capitula totius Bibliae, ordinati secundum ordinem Bibliae et in singulis versibus continentur plura capitula, sicut apparet in numero, qui dictionibus suprapositus est), que hace referencia a la tabula que se dispone a continuación, que se imprime por primera vez para esta edición (Copinger, 113). Dicha tabula está compuesta por 212 versos y ha sido atribuida a Alexander de Villa Dei (Setmüller, 1175); empieza con la siguientes palabras: «Incipit tabula super Bibliam per versus composita, omnes libros Biblie continens omniaque capitula et de quo agatur in eisdem capitulis.» ${ }^{10}$ En tercer lugar, después del índice de Villa Dei, aparece la tabula alfabética de Gabriele Bruno ${ }^{11}$, como indica el propio texto: «Tabula Alphabetica ex singulis libris et capitulis totius Bibliae, tam ex veteri, quam ex novo testamento, a reverendo in sacra Scriptura magistro Gabriele Bruno Veneto ordinis Minorum ministro provinciae terrae sanctae».

9 Encontramos una nota de procedencia en la primera hoja que alude al Convento de San Agustín de Valencia y el exlibris de D. Fernando José de Velasco, Fiscal del Supremo Consejo de Castilla, en el que se afirma: «Ex biblioteca D. Ferdinandi Josephi a Velasco in aula criminalis supremum castellae senatus fiscalis».

10 Alexander de Villa Dei (Villedieu-les-Poêles, Normandía - ca. 1150-1240/1250?) fue un franciscano dedicado al estudio de la gramática latina. Compuso una importante gramática publicada con el nombre de Doctrinable Puerorum que fue utilizada en toda Europa, hasta el s XVI, como texto para la enseñanza. Se le atribuye también un resumen de la Biblia en 212 versos.

11 Gabriele Bruno (Venecia, segunda mitad del s. XV-Venecia ca. 1508), franciscano, fue maestro de la Sagrada Escritura y de Teología. El 1 de noviembre de 1490 terminó de preparar una edición de la Vulgata de San Jerónimo acompañada de una tabula alphabetica y dos tratados: sobre Translatores Biblie y sobre Modi intelligendi sacram scripturam, en los que resume brevemente la historia de las traducciones de la biblia y explica los cuatro significados de los relatos bíblicos (literal, alegórico, moral y anagógico), respectivamente. Esta Biblia fue publicada por primera vez en Venecia por G. Paganini en 1492, con el título de la Biblia Latina. Fue objeto de muchas reediciones fundamentalmente gracias a la comodidad que resultaba de la tabula. En la edición que nosotros trabajamos de la Biblia Latina únicamente se incluye la tabula alphabetica. 
Bárbara Barberá Matías. Censura y expurgo en los incunables de la Biblioteca Histórica

\section{de la Universidad de Valencia}

En cuarto lugar, comienzan las epístolas de San Jerónimo, a Paulino: «Incipit Epistola Beati Hieronimi ad Paulinum presbyterum de omnibus divine historie libris» (Stegmüller, 284) y a Desiderio «Incipit prefatio Sancti Hieronimi presbyteri in pentateuchum»(Stegmüller, 285). En quinto lugar, se insertan los sumarios desde el libro del Génesis hasta el Paralipómenom, mientras que el resto de los libros de la Biblia (tanto del Viejo como del Nuevo Testamento) presentan sus sumarios al inicio o al final de cada capítulo, excepto el Psalterio que los incluye al final, tal y como se indica al comienzo de los sumarios: «Incipiunt summaria super Bibliam a libro genesis usque ad Paraliponemon et deinceps sunt de capitulo in capitulum, praeter Psalterium, que sunt postposita». A continuación aparece un grabado dividido en seis partes representando los trabajados de la creación del mundo tras el cual comienza el texto de la Biblia con su correspondiente glosa. El texto bíblico se completa con los prólogos de San Gerónimo y los comentarios del Cardenal Hug de Saint-Cher ${ }^{12}$ (ca. 1200-1263). Finalmente se insertan las Interpretationes Nominum Hebraicorum, que se presentan a modo de diccionario de las palabras hebreas que aparecen en el texto, atribuidas al teólogo inglés y arzobispo de Canterbury Stephen Langton ${ }^{13}$ (D'Armaury 1981) (ca. 1150 - Slindon, 1228).

Conocemos la fecha exacta en la que se revisó esta Biblia, el 1 de marzo de 1555, gracias a la nota de expurgo que figura al final de la tabula inicial. En esta misma nota el calificador afirma que quitó los errores en ella contenidos conforme «a la censura que para ello enviaron los señores del Consejo», como ya hemos analizado anteriormente. Esto permite pensar que se está refiriendo a la Censura Generalis de 1554. Esta censura se presenta como un índice expurgatorio e incluye un prefacio en el que se anotan entre otras cosas, las normas prácticas tenidas en cuenta en su redacción. Para abreviar el volumen de la obra los censores se limitan a señalar el libro y el capítulo bíblico que hay que corregir y se hace caso omiso de los títulos de los capítulos y de los sumarios, pues muy confusamente aluden al pasaje concreto al que se refieren, de hecho, «se decreta la supresión general de los sumarios o summae iniciales de las Biblias de formato grande y medio, así como de los edictos e índices, vista la cantidad de errores que contienen» (Tellechea Idígoras 1962: 98). Más concretamente, el texto de dicha Censura Generalis dice: «Iam vero quae sunt in titulis et summariis capitulorum adeo in plerisque confusa sunt, ut vix quisquam divinare queat ad quam partem textus referri non potuit, amittendum duximus, reliquentes id iudicio lectoris» (sign. b vii (r)) .Al mismo tiempo, el Inquisidor General Fernando de Valdés escribe lo siguiente en el prólogo:

[...] se han tomado muchas Biblias de diversas impressiones, en las quales se hallan muchos herrores, especialmente en los sumarios y en las adiciones y en algunos repertorios [...] por lo qual se pudiera iustamente mandar y vedar que todos los dichos libros en que assí ay los dichos

12 Identificados en Stegmüller, no 480, 485, 512, 513, 516, 522, 525, 529, 532, 535, 540, 544, 674, 690, 685, 699, 707, $715,728,736,747,752,765,772,780,783,793,807,806,812,818,822,823,824,825,839,834$ у 829.

13 ARMAURY D', E. (1981) "Le perfectionnement d'un instrument de travail au début du XIII ${ }^{\mathrm{e}}$ siècle: les trois glossaires bibliques d'Etienne Langton" en Culture et travail intellectuel dans l'occident médiéval, Paris. Ed. Editions du Centre National de la Recherche Scientifique.

SCRIPTA, Revista internacional de literatura i cultura medieval i moderna, núm. 4 / desembre 2014 / pp. 40 - 67 ISSN: 2340-4841 $\cdot$ doi:10.7203/SCRIPTA.4.4125 


\begin{abstract}
herrores se rasgassen o quemassen, de manera que no se pudiesse comunicar; mas avida consideración a que los dichos herrores no se hallan en el texto de la Sagrada Scriptura, sino en sumarios, adiciones y repertorios (como dicho es) y que el numero dellas es grande [...] fue acordado que se hiziesse cierta Censura en que se apuntasen y notasen todos los lugares en que en las dichas Biblias ay herrores y palabras sospechosas [...] (sign. a v (v) - a vii (r)).
\end{abstract}

De tal modo, la censura de esta Biblia probablemente se hizo en relación a estas recomendaciones, ya que todos los fragmentos censurados se encuentran en estos resúmenes, nunca en el texto de la biblia, y se limitan a cancelar una líneas muy breves, de manera que no se está corrigiendo en ningún momento el texto bíblico.

Por su parte, los Sermones Discipuli de tempore et de Sanctis (1497) ${ }^{14}$ de Johannes Herolt (1390-1468) presentan sólo dos fragmentos silenciados. Este autor, también conocido como Discipulus, de ahí el título de la obra, fue un dominico alemán representante de la nueva espiritualidad dominante en la Alemania del s. XV. La obra se divide en dos partes, los Sermones de tempore y los Sermones de sanctis. Herolt utilizaba historias ejemplares en sus sermones y una de las temáticas más recurrentes fueron los milagros de la Virgen María, que circularon impresos como las Promptuaria exemplorum y que se incluyen también en este volumen. La obra de Herolt fue incluída en el Índice de 1707, concretamente en la página 736 de dicho índice:

\begin{abstract}
Iohannes Herold, seu Herolt, non ille Hoechssentensis, qui pertinet ad 1 classem, sed vir pius, et catholicus, ordinis dominicani quem alii, Discipulum vocant. Ex opere quod inscribitur, Sermones Discipuli. Norimbergae 1514, et postea 1541, in eius operis fine, in Promptuario, quod inscribitur De miraculis Beate Merie Virginis, deleatur totum exemplum seu Miraculum duodecimum, quod incipit: "Quidam sanctus pater in spiritus audivit», etc. Constat viginti lineis.
\end{abstract}

El pasaje al que se refiere la anterior mención está todo él borrado, pero además el calificador ha censurado otro fragmento que no se indica en el Índice. En los márgenes de este primer fragmento censurado hay dos notas marginales de distintas manos, la primera de ellas dice: «miente» y la segunda afirma «y remiente, fue concevida María sin pecado original». En estas notas se corrige el texto original en el que se afirmaba lo contrario, es decir, que María nació con pecado original, al igual que el resto. Según la doctrina católica María fue concebida sin pecado original porque estaba destinada a ser la madre del hijo de Dios, lo que debía ser un acto puro y libre de pecado. Cuando la Biblia describe a María como «llena de gracia» se refiere a esta idea, de la que surge la imagen de la Inmaculada Concepción. En Lucas 1,28 podemos leer: et ingressus angelus ad eam dixit ave gratia plena Dominus tecum benedicta tu in mulieribus. Por este motivo María no puede ser presentada como una mujer equiparable al resto. El segundo fragmento cancelado, el exemplum XII, se manda borrar probablemente porque contradice la imagen de María soportando serenamente el martirio de Cristo y la sitúa al mismo nivel que el resto de los mortales, aguantando los mayores dolores del mundo, «qui fuissent dolores sui maiores in mundo»

14 Esta obra presenta también el exlibris de D. Fernando José de Velasco, Fiscal del Supremo Consejo de Castilla, en el que se afirma: «Ex biblioteca D. Ferdinandi Josephi a Velasco in aula criminalis supremum castellae senatus fiscalis». 


\section{de la Universidad de Valencia}

En la siguiente obra se cancela un pasaje relacionado con un episodio de los evangelios apócrifos. Se trata de la Legenda aurea sanctorum de Jacobo de Vorágine (Vorágine, 1228/1230-Génova, 1298). Este dominico consiguió cierto éxito como predicador y escritor de sermones destinados a la instrucción moral, su obra más importante es la Legenda aurea sanctorum, conocida también como Lombardica historia debido a que el autor dedica el segundo y último capítulo a la vida del Papa Pelagio e incluye un resumen sobre la historia de los lombardos. La obra fue redactada mediante la combinación de fuentes orales y escritas sobre la vida de los santos. Aunque de poco valor histórico, está impregnada de la poesía ingenua y escrita con viva imaginación y una fe sincera, lo que aseguró su popularidad. De hecho, fue objeto de muchas traducciones y tuvo una gran influencia sobre la poesía religiosa y la iconografía. El libro de Jacobo de Vorágine está censurado conforme al apéndice primero al expurgatorio de 1612, publicado en 1614, que se refiere a esta obra en la página 865 y manda borrar lo siguiente: «In legenda 6. Que est de Nativitate Domini Nostri Iesu Crbisti, fol. 7. col. 2 post illud: testis sue virginitatis extitit, dele usque ad: Quinto per miraculi, exclus».

En este pasaje Jacobo de Vorágine se refiere al mito de Salomé. En la religiosidad popular a finales de la Edad Media la idea del parto sin dolor y el vientre intacto de María tras dar a luz a Jesús eran la prueba de su virginidad perpetua, imagen que era transmitida a través de la historia apócrifa de la comadrona Salomé. Esta leyenda, originada en el Protoevangelio de Santiago [Santiago, 19-20], describe el nacimiento de Cristo. Cuenta cómo tras el parto comienza a extenderse el rumor de que una virgen ha dado a luz, idea que es puesta en duda por la comadrona Salomé, quien confiesa que no va creer que una virgen haya dado a luz hasta inspeccionar personalmente el cuerpo de la madre. Según la leyenda, la propia Salomé se lesionó la mano al tocar el cuerpo de María y dudar de su dignidad, y volvió a curarse al tocar al recién nacido y reconocer su error:

\footnotetext{
Y, al salir la partera de la gruta, vino a su encuentro Salomé, y ella exclamó: «Salomé, Salomé, tengo que contarte una maravilla nunca vista, y es que una virgen ha dado a luz; cosa que, como sabes, no sufre la naturaleza humana». Pero Salomé repuso: «Por vida del Señor, mi Dios, que no creeré tal cosa sino me es dado introducir mi dedo y examinar su naturaleza [Santiago, 19,3] Y, habiendo entrado la partera, le dijo a María: «Disponte, porque hay entre nosotras un gran altercado con relación a ti». Salomé, pues, introdujo su dedo en la naturaleza, mas de repente lanzó un grito, diciendo «iAy de mí! ¡Mi maldad y mi incredulidad tienen la culpa! Por tentar al Dios vivo se desprende de mi cuerpo mi mano carbonizada [Santiago, 20,1] [...] Y apareció un ángel del cielo, diciéndole: «Salomé, Salomé, el Señor te ha escuchado. Acerca tu mano al Niño, tómalo, y habrá para ti alegría y gozo [Santiago, 20,3\} Y se acercó Salomé y lo tomó, diciendo: «Le adoraré porque ha nacido para ser el gran Rey de Israel». Mas de repente se sintió curada y salió en paz de la cueva [...] [Santiago, 20,4] (Santos Otero 1996: 161-164)
}

Jacobo de Vorágine se apoya en esta leyenda cómo prueba de la virginidad perpetua de María (Lepp 2010: 125). Ciertamente el autor no está cometiendo ningún pecado ni cayendo en ningún error, pues no deja de afirmar la virginidad, castidad y pureza de la Virgen María. Sin embargo la leyenda de Salomé forma parte de los evangelios apócrifos y por tanto no está incluida en los textos canónicos aprobados por la Iglesia, de ahí la prohibición. 


\section{de la Universidad de Valencia}

El evangelio Apócrifo de Santiago es el que más ha influido en las narraciones de la natividad (Santos Otero 1996: 120). Tiene la finalidad de defender ante todo el honor de María, con un sentido apologético, que se manifiesta desde los primeros relatos. El autor expone argumentos a favor de la triple virginidad de María: antes del parto, durante el parto y después del parto (Santos Otero 1996: 127). En este sentido es especialmente interesante la historia de Salomé, que después es citada por Marcos ${ }^{15}$ como una de las asistentes a la crucifixión. Defiende incluso la concepción milagrosa de María siendo estériles sus padres, Ana y Joaquín. Esta concepción milagrosa es un paso decisivo para «la afirmación del dogma de la Inmaculada, ya que una de las razones de más peso con que tropezó la teología durante mucho tiempo para aceptarlo fue pensar que María era hija de la concupiscencia, como todos los demás hombres» (Santos Otero 1996: 124). Anteriormente, cuando hablábamos de la censura impuesta a la obra de Johannes Herolt, los Sermones discipuli de tempore et de sanctis, veíamos precisamente como la obra había sido expurgada por mostrar una idea contraria al dogma de la Inmaculada, diciendo que María sí había nacido con pecado original.

Probablemente estos relatos estén en el origen del culto mariano, dado que tuvieron mucha influencia en la época medieval, formando parte de la piedad popular. Las obras de este cariz, como los libros de horas o devocionarios, que suponían la base de las prácticas religiosas del pueblo, fueron objeto de persecución ya desde los primeros momentos de la Inquisición en el s. XVI y lo seguirán siendo hasta el s. XVIII. La justificación de estas prohibiciones era que tales ediciones contenían cosas curiosas y supersticiosas, que podían inducir a error a los indoctos, especialmente si estaban en vulgar, como pone de manifiesto una de las reglas generales del Índice de 1559 que mandaba recoger todas las obras «que tuvieren las dichas supersticiones o errores $\mathrm{u}$ ocasiones para errar y engañar a los simples y personas que no entiendan las tales supersticiones y usan de ellas en detrimento de sus conciencias y ofensas de Dios...» (Pinto Crespo 1983: 281). En definitiva esta idea manifiesta «el temor a no controlar la difusión de este tipo de literatura» como señala Virgilio Pinto Crespo (1983: 281).

En su afán por conformar una ideología y una historia de la Iglesia sin fisuras ni disidencias la Inquisición Española procedió a hacer desaparecer todas aquellas manifestaciones que divergiesen con la doctrina y la historia oficial. Es el caso del libro de Bartolomeo Platina (Piadena, 1421 - Roma, 1481) titulado Vitae Pontificum, donde se cancela el pasaje que habla sobre el episodio de la «Papisa Juana». El volumen de las Vitae Pontificum que estudiamos forma parte de una encuadernación facticia junto con una edición veneciana del Fasciculus Temporum de Werner Rolevinck de 1479. Platina, llamado realmente Bartolomeo Sacchi y conocido como il Platina, un hombre dedicado a las letras, fue preceptor de la casa de los Medici en Florencia y estuvo después al servicio del Papa Pio II. Con posterioridad mantuvo un enfrentamiento con su sucesor, Pablo II, a causa de la disolución del colegio de los compendiadores, del que formaba parte, lo que le llevó a la cárcel durante unos meses. Volvió a estar en prisión, junto con otros humanistas, entre 1468 y 1469

15 Marcos, 16.1: «Pasado el sábado, María Magdalena, María, la madre de Santiago, y Salomé, compraron aromas para embalsamar el cuerpo».

SCRIPTA, Revista internacional de literatura i cultura medieval i moderna, núm. 4 / desembre 2014 / pp. 40 - 67 ISSN: 2340-4841 · doi:10.7203/SCRIPTA.4.4125 


\section{de la Universidad de Valencia}

acusado de participar en el complot contra dicho Papa y como sospechoso de herejía. En venganza a esto Platina habló de manera desfavorable sobre Pablo II en sus Vitae Pontificum (escrita en 1479), describiéndolo como cruel y enemigo de la ciencia. Con Sixto IV gozó de mejor fortuna siendo nombrado director de la Biblioteca Vaticana y a él dedicó su obra más importante, las mencionadas Vitae Pontificum, una recopilación de las vidas de los santos.

Localizar la fecha de expurgo de esta obra ha sido una tarea compleja, ya que no se ha hallado una mención expresa de su autor en los Índices Inquisitoriales. Según la nota de expurgo, el libro ha sido censurado conforme al nuevo Índice Expurgatorio, en el año 1620, de forma que, excluyendo el apéndice de 1614 que no aporta mucho, el índice más cercano es el de 1612. En este índice se hace referencia a una obra titulada «Vitae Pontificum Romanorum» en la página 99, incluido en la tercera clase, es decir, aquellas obras cuyos autores no se conocen, pero que son objeto de expurgo o prohibición. No obstante no se detallan los fragmentos que deben ser cancelados. Probablemente esta mención se refiere a nuestra obra, que también era conocida por este título. Por otro lado, la Biblioteca Nacional conserva un ejemplar de la misma obra que contiene una anotación que «indica que ha sido expurgado el ejemplar de acuerdo con el expurgatorio de 1707 por Fr. Francisco del Hoyo», según el Catálogo de Incunables la Biblioteca Nacional de España elaborado por Julián Martín Abad (2010, I-1691). Revisando este Índice de 1707 comprobamos que la única mención a la obra de Platina es la misma que aparece en el de 1612, de lo que se deduce que efectivamente la obra fue censurada de acuerdo este Índice, a pesar de que hubiesen trascurrido años desde la publicación del mismo. Esto demuestra que no siempre las labores de expurgo eran inmediatas a la publicación los Índices.

Las Vitae Pontificum presentan una recopilación de las vidas de los papas y en este caso se borra casi por entero el pasaje que hace referencia a Juan VII (Johannes VII). En este fragmento se narra el famoso episodio de la papisa Juana. La historia de esta mujer, que asumió el pontificado con el nombre de Juan, fue reconocida por la Iglesia desde el s. XIII al XVI, de hecho en el s. XV la leyenda alcanzó tanta fama que se hizo figurar un busto de la papisa en la Catedral de Siena (Suárez 2005: 115). Tal y como relata Platina en el pasaje censurado, Juana fue una joven nacida en Maguncia de gran sabiduría e inteligencia. Durante su juventud se enamoró de un monje benedictino con el que huyó a Atenas. A la muerte de éste, Juana se disfrazó de hombre, adoptando el nombre de Johannes Anglicus, e ingresó en el sacerdocio. Fue nombrada Cardenal y posteriormente Papa, a la muerte de León IV en el 855. Dos años después la papisa quedó embarazada, un embarazo que supo disimular hasta que dio a luz durante una procesión dirigida a la iglesia de Letrán, entre el Coliseo y San Clemente, muriendo a causa de los dolores del parto, le sucedió Benedicto III. La noticia más antigua de esta leyenda se encuentra en la Chronica universalis Mettensis (ca. 1250) y es atribuida a Juan de Mailly. En 1265 la Chronica de Erfurt se refiere también a ella, pero situándola a la muerte de Sergio III en el año 914 (Suárez 2005: 115). Por su parte, el dominico Martín de Troppau llega a afirmar que durante un tiempo los papas evitaron pasar en sus procesiones por el lugar donde dio a luz y murió la papisa. Sin embargo, según Luis Suárez no existe posibilidad cronológica de insertar 
Bárbara Barberá Matías. Censura y expurgo en los incunables de la Biblioteca Histórica

\section{de la Universidad de Valencia}

el pontificado de la papisa Juana entre León IV y Benedicto III, porque ambos se sucedieron sin solución de continuidad (Suárez 2005: 115), por lo que la historia se reduciría a una mera leyenda. La Iglesia ha negado la existencia de la papisa Juana desde el s. XVI hasta la actualidad. Sin embargo, en el s. XV Bartolomeo Platina sí la incluye en su obra, describiéndola además como una persona con un gran conocimiento de las Sagradas Escrituras, que alcanzó autoridad y respeto hasta el punto de ser elegida papa de común acuerdo, «omnium consensu Pontifex crearetun». Platina reconoce que es una historia que se ha transmitido entre el pueblo y ha sido contada por autores «inciertos», sin embargo, afirma que la historia no puede considerarse enteramente increíble:

\footnotetext{
Haec quae dixi vulgo feruntur, incertis tamen et obscuris auctoribus: quae ideo ponere breviter et nude institui, ne obstinate nimium et pertinaciter omisisse videar, quod fere omnes affirmant: erremus etiam non hac in re cum vulgo, quanquam appareat, ea, quae dixi, ex his esse, quae fieri posse creduntur (sign. m 4).
}

Es fácil entender porqué se cancela este episodio en el s. XVII, momento en el que se censura el libro de Platina, dado que no forma parte de la historia aceptada por la Iglesia católica, más aún cuando el autor admite que pudo haber sido verdad aunque sea de forma relativa. En este sentido, aceptar la existencia de una mujer pontífice sale fuera de la cosmovisión que la Inquisición trata de imponer, tanto porque contradice la historia oficial de la Iglesia católica, como por que asume la idea de una mujer caracterizada por poseer una autoridad e inteligencia al nivel de los dirigentes de la Iglesia, a los que llega a engañar hasta convertirse en Papa.

El mismo problema se sucede en la siguiente obra analizada, el Fasciculus Temporum de Werner Rolevinck publicado en 1485 en Venecia, procedente del Convento de los Trinitarios Descalzos. El alemán Wernerius Rolevinck (Westfalia, 1425 - Colonia, 1502), fue monje de la Cartuja de Santa Bárbara en Colonia. Cultivó el campo de la teología y de la historia y sus obras tuvieron mucha difusión, especialmente el Fasciculus temporum. Esta obra consiste en un compendio de historia universal desde la creación del mundo, dispuesto en forma de anales concordados con la historia de Israel e ilustrados con vistas de ciudades como Roma o Siracusa y referencias a personajes cuyas cronologías se insertan en círculos (Escolar 1994: 69). El resultado es una obra en la que el texto se mezcla con los abundantes grabados xilográficos que configuran las páginas y no presenta, por tanto, la forma típica del libro en una o dos columnas propia de la época. Esta obra fue además el primer libro impreso en España con ilustraciones, en la edición de Bartolomé Segura y Alfonso del Puerto, del año 1480 (Escolar 1994: 69).

En la tabula, al inicio del libro, se cancela el nombre de «Ioannes anglicus natione». En el fol. 49r se anula un fragmento de texto, todo el que corresponde a este mismo personaje. En este caso, al no contar con una nota de expurgo que nos oriente, ha sido más difícil establecer el momento de expurgo. Los Índices de 1640 y 1707 mencionan el Fasciculus temporum entre las obras de tercera clase, y además el pasaje suprimido coincide expresamente con el que en estos catálogos se manda anular. Es complicado establecer en función de cual se llevó a cabo la censura, por lo que no 
podemos ofrecer una fecha exacta, pero sí sabemos que la obra fue censurada en el siglo XVII (en la segunda mitad), o bien a principios del XVIII. En el Índice de 1640 (p. 467) y después en el de 1707 (p.481), se dice:

\begin{abstract}
Germanicorum rerum scriptores, septem tomis [...] In fasciculus temporum. Sexta mundi aetate, anno Crhisti DXIII, fol 54. pagin. 2. a medio, ad verba illa textus, Iste: «Felix iussit infirmos», etc. adscrito in margine, "caute lege». Eadem aetate, anno Christi DCCCLXIIII, fol. 66, pagina. 2, a medio, dele verva illa textus iste: «Ioannes Anglicus cognomine», etc. Ubicumque, et quomodocumque talis fabula reperiatus delenda. Eadem sexta mundi aetatem, anno Crbisti MIII, fol. 71, pag.I, a medio, ad verba illa texto, iste «Sylvester factus est», etc, dele «fabulorum, quod Sylvestro refert.
\end{abstract}

En este caso sólo se lleva a cabo una de las tres correcciones, la segunda de ellas, que afecta de nuevo al pasaje de Juan VII, el episodio de la papisa Juana, al igual que se contaba en las Vitae Pontificum. Werner Rolevinck describe brevemente el suceso, sin aportar tanto detalle. Sobre este episodio y su censura nos remitimos a lo descrito anteriormente, en el caso de la obra de Platina.

Hasta ahora, exceptuando la obra de Dante que podemos encuadrar entre las obras de poesía medieval, hemos visto únicamente obras de género religioso, sin embargo, los libros de los clásicos greco-latinos tampoco escaparon al control de los calificadores del Santo Oficio. Tal es el caso del volumen que contiene las obras de Virgilio, procedente del convento de Montesa, impreso en 1493. Virgilio Publio Marón (Virgilio, 70 a.C.-Brindisi, 19 a.C.) es uno de los autores clásicos más conocidos. Sus obras fueron muy elogiadas durante la Edad Media y se convirtió en una de las figuras fundamentales del Renacimiento, de hecho, fue escogido por Dante para guiar su viaje por el infierno y el purgatorio. En su primera obra, las Églogas o Bucólicas, donde ensalza la vida pastoril, canta a la llegada de un niño que anuncia una nueva época: «Tú, casta Lucina, sé propicia al niño que ahora nace, con él la raza de hierro dejará de serlo al punto y por todo el mundo surgirá una raza de oro» [Égloga IV , 8] «Recibirá aquel niño la vida de los dioses y con los dioses contemplará a héroes mezclados y a él mismo lo verán entre ellos y regirá el mundo apaciguado por las virtudes de su padre» [Égloga IV, 15] (Virgilio 1990: 187-188). Virgilio se está refiriendo al final de la guerra y la llegada de una época de paz en Roma, sin embargo, la Égloga IV fue interpretada posteriormente por los autores católicos como la anunciación del nacimiento de Cristo, lo que incluyó a Virgilio entre los profetas de la religión católica. Virgilio escribió otras dos obras, la Eneida, en la que el protagonista simboliza alegóricamente al emperador Augusto que aparece como fundador de Roma e hijo de dioses, y las Georgicas, donde proclama la necesidad de restablecer el mundo campesino tradicional. Sobre las composiciones que suelen aparecer con el título Appendix Vergiliana, se duda que la autoría corresponda al Virgilio, considerándose esta colección el resultado de atribuciones erróneas y falsificaciones voluntarias.

En el volumen que trabajamos, bajo el título Opera se incluyen distintas obras. En primer lugar los libros de Virgilio, las Bucolicas y las Georgicas, comentadas Mauro Honorato Servio, Elio Donato, Cristoforo Landino y Antonio Mancinelli, además de la obra Aeneidos (Eneida), a la que se añade el liber XIII del humanista y escritor italiano Maffeo Vègio (Lodi, 1406/1407 - Roma, 1458), con 
Bárbara Barberá Matías. Censura y expurgo en los incunables de la Biblioteca Histórica de la Universidad de Valencia

comentario de los anteriormente mencionados Mauro Honorato Servio, Elio Donato y Cristoforo Landino. Maffeo Vègio pretendía con su obra continuar la Eneida de Virgilio, que se consideraba inacabada. A continuación se añaden otras obras: una serie de textos agrupados como el Appendix Vergiliana atribuido a un seudo-Virgilio, con comentario de Domizio Calderino, un texto de Ausonio y otros tantos de un tal seudo-Ausonio, con comentario del mismo Calderino. Todas estas obras se atribuyen a Virgilio, el único que consta como autor (exceptuando la obra atribuida a Maffeo Vègio). La inclusión de obras de autores menores en los volúmenes de los autores principales supuso una práctica común en la época, ya que permitía que circulasen los títulos de estos autores menores cuando de otro modo hubieran tenido más problemas.

Únicamente se ha cancelado el título del comentario que precede a las obras de Virgilio. La línea anulada dice: «ANTONIUS MANCINELLUS VELITERNUS URSO URSINO HEROI CLARISSIMO PONTifici Thean. Ac Gymnasii almae Urbis Rectori». Corresponde al título del comentario de Antonio Mancinelli. La nota de expurgo nos ofrece una fecha concreta, 19 de junio de 1585. Probablemente la censura esté en relación con el Índice de Quiroga. Sin embargo, lo cierto es que no hemos encontrado ninguna referencia a esta obra en este Índice, ni tampoco a Antonio Mancinelli o a Orso Orsini, a quien Mancinelli dedica el comentario, cuyo nombre es borrado. Desconocemos porqué se llevó a cabo esta actuación, sin descartar que estuviese originada en un edicto o carta acordada en concreto.

Antonio Mancinelli (Velletri, 1452 - Roma, ca. 1505) fue un importante humanista italiano dedicado a la enseñanza, autor de numerosos poemas, comentarios y estudios de gramática en los que se mostraba en contra del antiguo método de aprendizaje del latín. Desde 1486 hasta 1490/91 ocupó un cargo en el Studium Urbis, periodo durante el cual tuvo como promotores al abogado Domenico de Bounauguri y al rector Orso Orsino, a quien le dedicó su comentario a las obras de Virgilio; de hecho, Mancinelli siempre trató con gratitud a la familia Orsini. Este comentario formó parte del discurso de inauguración de la cátedra en 1486/87, en el que también comentó a otros autores como Juvenal, Valerio Máximo u Horacio. De estos, sólo publicó el comentario a Virgilio, en una edición en la que aclamaba las coplas del afamado erudito de la antigüedad clásica Pomponio Leto (Lucano, ca.1428-Roma, 1498). Este hecho merece la atención debido a que en esos años la obra de Virgilio había sido objeto de estudio del mismo Leto, que apenas unos meses antes de la edición de Mancinelli había repudiado públicamente una edición falsa de su obra nacida en realidad de las notas de uno de sus estudiantes. La mención a Leto hecha por Mancinelli aumentó su éxito, que se fue consolidando en los años siguientes, hasta que su comentario fue añadido en 1491-92 a los de Servio, D. Calderino y C. Landino, dando lugar a la edición de las obras de Virgilio que nosotros estudiamos ${ }^{16}$.

16 Dižionario biográfico degli italiani (1960-2000) Roma, Ed. Istituto della Enciclopedia Italiana, tomo 68. Consultado en el portal online: Treccani. Enciclopedia italiana on-line. (http://www.treccani.it/)

SCRIPTA, Revista internacional de literatura i cultura medieval i moderna, núm. 4 / desembre 2014 / pp. 40 - 67 ISSN: 2340-4841 · doi:10.7203/SCRIPTA.4.4125 
Bárbara Barberá Matías. Censura y expurgo en los incunables de la Biblioteca Histórica

\author{
de la Universidad de Valencia
}

\title{
3. Conclusión
}

Los ocho incunables censurados de la Biblioteca Histórica de la Universidad de Valencia son una muestra más del espíritu de las primeras etapas de la Inquisición, en los siglos XVI y XVII, cuando las preocupaciones de los censores se centraban en cuestiones de fe, relacionadas con la doctrina católica, y no tanto en cuestiones sociales o morales, como la indecencia o el libertinaje, que si serán objeto de censura en épocas posteriores y que afectarán a multitud de obras de poesía, novelas y piezas teatrales. En las censuras a las obras de Ángel de Clavasio, Herolt Johannes y Jacobo de la Vorágine se está atendiendo a cuestiones doctrinales y de teología moral, reflejando la preocupación de la Iglesia ante la fama de las obras más cercanas al pueblo, como ocurría con los devocionarios y las obras de piedad popular, que podían llevar a error a los fieles menos doctos; en este sentido reviste especial interés la figura de María. Del mismo modo, la Inquisición velaba por la construcción y la defensa de una historia oficial, acorde con la doctrina católica, de manera que cualquier desviación que enturbiara esta imagen no era permitida, como podían ser leyendas como la de la papisa Juana, de gran tradición popular, que es censurada en las obra de Bartolomeo Platina y de Werner Rolevink, o de igual modo, la mala imagen del papado que podía inferirse de la obra de Dante.

La Inquisición siempre tuvo claro el poder de la palabra escrita y del libro como vehículo de transmisión, como se pone de manifiesto en el Prólogo al Índice de 1612 del Inquisidor General Bernardo de Sandoval y Rojas, donde podemos leer: «I es cierto, que por ningún medio se comunica y delata como por el de los libros que, siendo maestros mudos, continuamente hablan y enseñan a todas horas (...) Deste tan eficaz i pernicioso medio se ha valido siempre el común adversario de la verdad católica».

El Santo Oficio reaccionó ante la herejía con argumentos y largos tratados y disertaciones, pero también lo hizo de una forma más violenta mediante el castigo físico de los herejes y al mismo tiempo de sus libros. Como señala Francisco Gimeno Blay, «aunque se intente demostrar lo contrario las ideas de un texto escrito permanecen en el tiempo y siguen diciendo lo mismo que exponían con anterioridad a cualquier discusión teórica» (Gimeno Blay 2001: 2) Desde tiempos más antiguos la destrucción física de los libros ha sido la respuesta más fácil ante el miedo a la palabra escrita. La quema de libros supone, sin duda, «la violencia extrema contra la Cultura Escrita» (Gimeno Blay 2001: 2). La censura inquisitorial contribuyó a crear un clima de desconfianza donde la lectura era vista por gran parte de la sociedad, en su mayoría analfabeta, como una actividad peligrosa, tal y como ilustra el siguiente pasaje, extraído del episodio de Los alcaldes de Daganæo, en Las Novelas Ejemplares de Miguel de Cervantes:

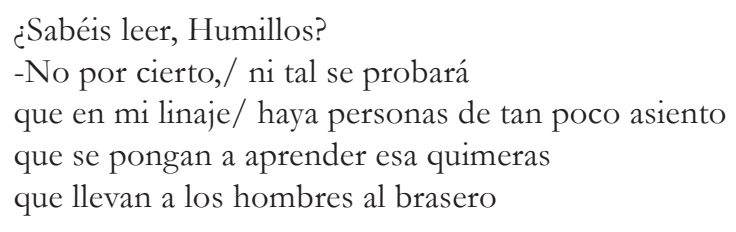

SCRIPTA, Revista internacional de literatura i cultura medieval i moderna, núm. 4 / desembre 2014 / pp. 40 - 67 ISSN: 2340-4841 · doi:10.7203/SCRIPTA.4.4125 


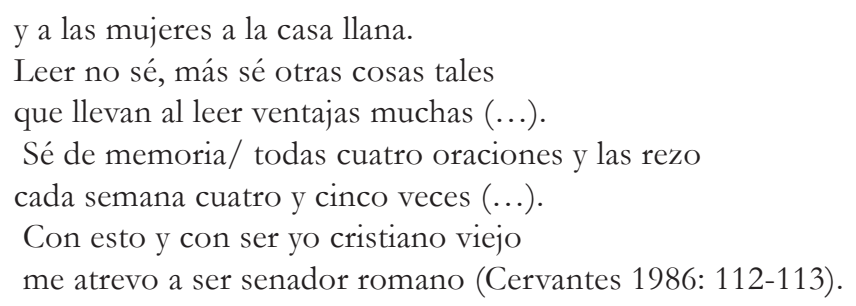

No debemos considerar el libro como un objeto inerte, sino como parte de un patrimonio histórico que muestra signos de uso. En él no sólo encontramos la voluntad del autor, sino que generalmente existen huellas de los lectores, desde las notas marginales hasta las notas de procedencia y de propiedad que nos ayudan a reconstruir la historia del libro. Pero también existen intervenciones negativas, aquellas que tratan de acotar la lectura y limitarla en un sentido único y preciso «en base a un control autoritario y una manipulación de la memoria» (Gimeno Blay 2000: 19). Son varios los motivos que conducen a la destrucción de la palabra escrita y cuando es el poder el que dirige este acto, el objetivo que persigue es acabar con la heterodoxia «para extirpar las ideas contrarias a la norma, las cuales atentan contra el mismo ejercicio de la autoridad» (Gimeno Blay 2000: 19). La realidad es que la memoria formada por estas últimas intervenciones con sentido negativo es casi más fuerte que la creada por las que tienen un carácter positivo y constructivo, dado el poder que la Iglesia ha tenido sobre la formación de la cultura occidental. 
Bárbara Barberá Matías. Censura y expurgo en los incunables de la Biblioteca Histórica de la Universidad de Valencia

\section{Bibliografía}

\section{Incunables:}

Alighieri, Dante (1265-1321) La Commedia, / col commento di Cristoforo Landino. Rime diverse. — Venezia : Piero [de' Piasi] Cremonese (18 noviembre, 1491); Fol.

Ángel de Clavasio, Beato (ca. 1410-1495) Summa de casibus conscientiae. -Lugduni : [MartinusHavard(?)] (19 septiembre, 1500) ; $4^{\circ}$.

Biblia. Latín. Biblia latina, / cum tabula Gabrielis Bruni. — Venetiis : Simon Bevilaqua (8 mayo $1498) ; 4^{\circ}$.

Herolt, Johannes (O.P.) (ca. 1380-1468) Sermones Discipuli de tempore. (I). et de sanctis. Promptuaria exemplorum et de miraculis Beatae Virginis Mariae (II). — [Lugduni : Johannes de Vingle] (30 julio, 1497) ; $4^{\circ}$.Partes I-II

Jacobo de Vorágine, Beato (ca. 1228-1298) Legenda aurea sanctorum. — Venetiis : Antonius de Strata et Marcus Catanellus (1 julio, 1480) ; Fol.

Platina, Bartolomeo. Vitae Pontificum. — [Venetiis] : Johannes de Colonia et Johannes Manthen (11juni o, 1479); Fol.

Rolevinck, Wernerius. Fasciculus temporum, vel Chronica ab initio mundi. — Venetiis : Erhardus Ratdolt (8 septiembre, 1485); Fol.

Virgilio Marón, Publio. Opera (Bucolica, vel Eclogae. Georgica. Aeneis), / cu m commentariis Servii Mauri Honorati, Aelii Donati, Christophori Landini et Antonii Mancinelli, addito libro XIII Maphaei Vegii XII Aeneidos. Seudo-Virgilio: Appendix Vergiliana (Moretum.Priapeia et Catalepton. Dirae, cum comm. Domitii Calderini. Copa. Aetna. Ciris.Culex. Elegia in Moecenatem. Omnia haec, cum comm. eiusdem Calderini). Deseipso. Ausonio: De aetatibus animantium (Idyll.V). Seudo-Ausonio: De aerumnis Herculis. De Musarum inventis. De est et non, cum comm. Domitii Calderini. Deviro bono. De rosis nascentibus. Omnia haec cum comm. eiusdem Calderini.Duodecim Sapientes Romae: Carmina plura (De laude hortuli, etc. notata supra ad C.6011). — (Venetiis : Bartholomaeus de Zanis : impens. Lucae Antonii de Giunta (31 julio, 1493); Fol.

\section{Índices inquisitoriales:}

Catalogi librorum reprobatorum \& praelegendor $u$ ex indicio Academiae Lonaniensis. Cum edicto Caesareae Maiestatis eunlgati. — Pinciae: Ex officina Francis. Ferdi. Corduben., 1551

Cathalogus libror ${ }^{-} u$, qui probib etur mandato Illustrissimi \& Reuerend. D.D. Ferdinandi de Valdes Hispale ${ }^{-} n$. Archie pi, Inquisitoris Generalis Hispaniae ... - Pinciae: Quorum iussu \& licentia Sebastianus Martinez Excudebat, 1559 
Bárbara Barberá Matías. Censura y expurgo en los incunables de la Biblioteca Histórica de la Universidad de Valencia

Censura generalis contra errores quib [us] recens haeretici sacram scripturam asperserunt / edita a Supremo Senatu Inquisitionis aduersus hereticam pranitatem \& apostasiam in Hispania \& aliis regnis \& dominiis Cesareae Magestatis constituto. — Pinciae: ex officina Francis. Ferdinan. Corduben, [s.a.]

Index et catalogus librorum probibitorum / mandato ... D.D. Gasparis a Quiroga Cardinalis Archiepiscopi Toletani ac in regnis Hispaniarum Generalis Inquisitoris denuo editus ... - Madriti: apud Alphonsum Gomezium ..., 1583

Index Expurgatorius Hispanus / ab ... Didaco Sarmiento et Valladares inceptus et ab ... Vitale Marin perfectus anno MDCCVII. — [S.l. : s.n., s.a.]

Index librorum expurgatorum ... / D.D. Gasparis Quiroga Cardinalis \& Archiep. Toletani Hispan. generalis Inquisitoris iussu editus ... — Madriti: apud Alfonsum Gomezium ..., 1584

Index librorum probibitorum et expurgatorum / Illmi. ac Rmi. D.D. Bernardi de Sandoual et Roxas S.R. E. Presb. Cardin... Archiepisc. Toletani... auctoritate et iussu editus... - Madriti: apud Ludouicum Sanchez..., 1612

Index librorum probibitorum et expurgatorum... Bernardi de Sandoval et Roxas... archiepisc. Toletani... / generalis inquisitoris regii... auctoritate et iussu editus... — Madriti: apud Ludovicum Sanchez..., 1612 (1614)

Nouns index librorum probibitorum et expurgatorum / editus auctoritate \& iussu ... Antonii Zapata ... Hispali : ex typographaeo Francisci de Lyra, 1632

Novissimus librorum probibitorum et expurgatorum index pro Catholici Hispaniarum Regnis Philippii IV ... Madriti: ex Typographaeo Didaci Diaz, 1640

Catálogos y obras de referencia:

Catálogo Colectivo del Patrimonio Bibliográfico Español (CCPB). Ministerio de educación, cultura y deporte: http://www.mcu.es/bibliotecas/MC/CCPB/index.ht ml

Copinger, W. A. (2007) Incunabula biblica or the first half century of the latin Bible being a bibliographical account of the various editions of the latin Bible between 1450 and 1500 : with an appendix containing a chronological list of the editions of the sixteenth century. Mansfield Centre (Connecticut).

Diz̨ionario biográfico degli italiani (1960-2000) Roma, Ed. Istituto della Enciclopedia Italiana.

Douay-Rehims Bible on-line (http://www.drbo.org/)

García Craviotto, F. (1989). Catálogo de Incunables en Bibliotecas Españolas. Madrid. Ed Ministerio de Cultura. Dirección General del Libro y Bibliotecas

Gesamtkatalog der Wiegendrucke (GW). Staatsbibliothek zu Berlin. http://www. gesamtkatalogderwiegendrucke.de/

Incunabula Short Title Catalogue (ISTC). British Library: http://www.bl.uk/catalogues/istc/

Kenney, E.J. y Clausen, W.V. (eds.) (1989-1990) Historia de la literatura clásica latina. Madrid, Ed. Gredos. T.II 
Bárbara Barberá Matías. Censura y expurgo en los incunables de la Biblioteca Histórica de la Universidad de Valencia

Lexikon des mittelalters (1977-1998) Munchen, Ed. Lexma.

Martín Abad, J. (2010) Catálogo bibliográfico de la colección de incunables de la Biblioteca Nacional de España, Madrid, Ed. Biblioteca Nacional de España.

Palanca Pons, A., García Morales, J., Gómez Gómez, M.D.P. (1981) Catálogo de los incunables de la Biblioteca Universitaria de Valencia, Valencia, Ed. Universidad de Valencia.

Stegmüller, F. (1959-1989) Repertorium biblicum Medii Aevi, Madrid, Ed. Consejo Superior de Investigaciones Cientificas, Instituto Francisco Suárez.

Treccani. Enciclopedia italiana on-line. (http://www.treccani.it/)

VIAF (Virtual International Authority File)

Virtual International Authority File (VIAF). (http://viaf.org/)

VV.AA. (2003) Enciclopedia universal ilustrada europeo-americana, Madrid, Ed. Espasa-Calpe.

\section{Bibliografia:}

Alighieri, D. (1976) La Divina Comedia, a cura di Natalino Sapegno, Firenze, Ed. La Nuova Italia Editrice.

——. (1993) Divina Comedia. Edición de Giorgio Petrocchi y Luis Martínez Merlo, Madrid, Cátedra.

Armaury D’, E. (1981) «Le perfectionnement d'un instrument de travail au début du XIII ${ }^{\mathrm{e}}$ siècle: les trois glossaires bibliques d'Etienne Langton» en Culture et travail intellectuel dans l'occident médiéval, Paris, Ed. Editions du Centre National de la Recherche Scientifique.

Balsamo, L. (1998) La bibliografía. Historia de una tradición, Gijón, Trea.

Bujanda, J.M. de (1984) Index de l'Inquisition espagnole: 1551, 1554, 1559, Genève, Ed. Sherbrooke, Université de Sherbrooke, Centre d'Etudes de la Renaissance.

. (1993) Index de l'Inquisition espagnole: 1583, 1584, Genève, Ed. Sherbrooke, Université de Sherbrooke, Centre d'Etudes de la Renaissance.

- (2002). Index librorum probibitorum, 1600-1966. Genève, Ed. Sherbrooke, Université de Sherbrooke, Centre d'Etudes de la Renaissance.

Cabeza Sánchez-Albornoz, $M^{a}$ C. (2000) La biblioteca universitaria de Valencia, Valencia, Universitat de València.

Cabezas Fontalla, S. (2005), En torno a la impresión del «Catálogo de libros prohibidos y expurgados» de 1612. Documenta \& Instrumenta, 3, pp. 7-30.

Cerrón Puga, Ma .L. (1996). «La censura literaria en el Index de Quiroga (1583-1584)» En García De Enterría, Ma . C. Y Cordón Mesa, A. (Eds.). Actas del IV Congreso Internacional de la Asociación Internacional Siglo de Oro (AISO). Alcalá de Henares, Universidad de Alcalá, pp. 409-417.

SCRIPTA, Revista internacional de literatura i cultura medieval i moderna, núm. 4 / desembre 2014 / pp. 40 - 67 
Bárbara Barberá Matías. Censura y expurgo en los incunables de la Biblioteca Histórica de la Universidad de Valencia

De Cervantes, M. (1986) «La elección de los alcaldes de Daganzo» en CERVANTES, M. Entremeses. Edición, introducción y notas de Eugenio Asensio. $3^{a}$ edición. Madrid, Castalia, pp. 112-113.

Defourneox, M. (1973), Inquisición y censura de libros en la España del s. XVIII, Madrid, Taurus.

Escolar, H. (1994) Historia ilustrada del libro español. De los incunables al s. XVIII, Madrid, Fundación Germán Sánchez Ruipérez.

García Cárcel, R. y Burgos Ricón, J (1993) «Los criterios inquisitoriales en la censura de libros en los ss. XVI y XVII», Historia Social, 14, pp. 97-109.

García Cárcel, R. y Moreno Martínez, D. (2000) Inquisición. Historia crítica, Madrid, Ed. Temas de Hoy.

Gimeno Blay, F. M. (2001) «Quemar libros... ¡Qué extraño placer!», Arché, 8, pp. 1-32.

- (1999) «Manuscrits medievals i incunables», en Els tresors de la Universitat de València: 30 abril, 1499-1999, Valencia, Universitat de València, Patronat Cinc Segles, pp. 145-152.

- (2000) El tresor bibliográfic entre saber i imaginació, en Cinc segles i un dia [Exposició], Valencia, Universitat de València, pp. 61-76.

Lepp, A. J. (2010) The Rooster's Egg: maternal metaphors and medieval man, Toronto, University of Toronto, Departament of History.

Márquez, A. (1985) «Los libros prohibidos en el s. XVII: Edición crítica de los Índices inquisitoriales españoles de 1551, 1554 y 1559», Arbor, 474, pp. 93-107.

Martínez Millán, J. (1980) «Aportaciones a la formación del Estado moderno y a la política española a través de la censura inquisitorial durante el periodo 1480-1559», en Villanueva Pérez, J. (Dir.). La Inquisición Española: nueva visión, nuevos horizontes, Madrid, Siglo XXI de España, pp. 537-578.

Pardo Tomás, J. (1991) Ciencia y censura: la Inquisición española y los libros científicos en los siglos XVI y XVII, Madrid, Consejo Superior de Investigaciones Científicas.

Suárez, L. (2005) «Los Papas de la Edad Antigua y Medieval» en Paredes, J. (dir.) Diccionario de los papas y concilios, Barcelona, Ed. Ariel, pp, 10-219.

Pinto Crespo, V. (1980) «Institucionalización inquisitorial y censura de libros», en Villanueva Pérez, J. (dir.), La Inquisición Española: nueva visión, nuevos horizontes, Madrid, Ed. Siglo XXI de España, pp. 513-534.

—. (1983). Inquisición y control ideológico en la España del s. XVI, Madrid, Taurus.

—_. (1984) «La censura: sistemas de control e instrumento de acción», en Alcalá, A. et alii, Inquisición española y mentalidad inquisitorial, Barcelona, Ariel, pp. 269-287.

—_. (1989) «Pensamiento, vida intelectual y censura en la España de los ss. XVI y XVII», Edad de Oro, VIII. 182-192.

Polastron, L. X. (2007) Libros en llamas: historia de la interminable destrucción de bibliotecas, México, D.F. Ed. Fondo de Cultura Económica. Libraria. 
Bárbara Barberá Matías. Censura y expurgo en los incunables de la Biblioteca Histórica de la Universidad de Valencia

Pons Alós, V. (2012) «Los expurgos de la biblioteca del Patriarca Ribera», en Callado Estela, E. El Patriarca Ribera y su tiempo. Religión, cultura y politica en la Edad Moderna, Valencia. Institució Alfons el Magnànim, pp. 345-363.

Reyes Gómez, F. (2000) El libro en España y América. Legislación y censura (siglos XV-XVIII), Madrid, Ed. Arco/Libros S.L.

Santos Otero, A. (1996) Los Evangelios Apócrigos, Madrid, Biblioteca de Autores Cristianos.

Tellechea Idígoras, J. J. (1962) «La censura de Biblias de 1554», Anthologica Annua, 10, pp. 89-142.

Virgilio Marón, P. (1990) Bucólicas, Geórgicas, Apéndice Vergiliano, Biblioteca Clásica Gredos, Madrid. 